\title{
Variability of sea surface temperature differences between western Pacific Ocean and eastern Indian Ocean related to ENSO events
}

\author{
Hasti Amrih Rejeki ${ }^{1, a,}$, Kunarso $^{2, b}$ and Munasik ${ }^{2}$ \\ ${ }^{1}$ School of Meteorology Climatology and Geophysics Indonesian Agency for Meteorology \\ Climatology and Geophysics (BMKG), Tangerang Selatan, Indonesia \\ ${ }^{2}$ Faculty of Fisheries and Marine Science, Diponegoro University, Semarang, Indonesia \\ a.hastiamrihrejeki@gmail.com, b. kunarsojpr@yahoo.com \\ *hastiamrihrejeki@gmail.com
}

Keywords: $\quad$ Variability, sea surface temperature, ENSO

Abstract: The existence of current circulation which flowing from the Pacific Ocean to the Indian Ocean passing through Indonesia causes a connection between those two oceans. That current will be affected if there is a global scale disruption such as the occurrence of ENSO (El Nino Southern Oscillation). The occurrence of ENSO will cause the sea surface temperature (SST) variability in those two oceans. This study examines about the variability of SST in the eastern Indian Ocean and western Pacific Ocean at the occurrence of ENSO and the trend of SST differences between those two regions which is directly connected by the current which passing through Indonesia that called as Indonesia Throughflow. This study utilized SST data from 1982 to 2015 obtained from IRI/Ideo Climate Data Library to analyze the variability of SST at the study area and SST anomaly data of Nino 3.4 region obtained from NOAA to represent the occurrence of the ENSO. The results showed that in January, February, and March SST in the eastern Indian Ocean were higher than the SST in the western Pacific Ocean and the SST differences between those two oceans became larger when El Nino happened than while the occurrence of La Nina. In April, May, June, July, August, September, October, and November the trends of SST in western Pacific Ocean are higher than the SST in the eastern Indian Ocean and it had the same condition with El Nino and La Nina and tend to be no differences from the normal conditions. In December, where the value of the SST in western Pacific Ocean remains higher than the SST in eastern Indian Ocean but at the time of El Nino, the SST differences becomes smaller than when La Nina happened.

\section{Introduction}

Indonesia is passed by a part of the global ocean circulation known as the Indonesia Throughflow (ITF). ITF is a current which is a part of ocean circulation system that moves from Pacific Ocean to Indian Ocean and it through the Indonesian waters [1]. Its current flow path takes the mass of water 
from the Pacific Ocean to the Indian Ocean [2]. Determining the existence of ITF can be done by observing the sea surface temperature (SST) variability around Indonesia as one of its important indicators [3].

As it known, the ITF is a part of the global circulation [1] so, it will be affected by global weather and climate phenomena such as ENSO. ENSO is a phenomenon related to the variability of sea surface temperature (SST) which will affect the condition of SST in almost parts of the world. In this case, the Pacific region that will be affected directly. The El Niño phenomenon is characterized by positive SST anomalies in the Pacific Ocean. El Niño deals with the weak and warm ocean currents along the coast of South America, which replaces the cold currents of the Peruvian currents [4]. In fact, the Indian Ocean and the Pacific Ocean have strong connection to each other and the radius of warm temperature in Indian Ocean basin triggered by El Niño on interannual time scale [5]. Generally, the SST in western Indian Ocean is lower than the SST in eastern Pacific Ocean [6].

Sea surface temperature (SST) is a dominant indicator that is often to be used to see the symptoms of climate anomalies. Climatic anomalies that often recur essentially have a dependence between the dynamics of the oceans and the atmosphere [7]. Related to the SST conditions around the ITF path, the study in the Timor Sea region indicated that ENSO gave an impact to the variability of SST in that area [2]. When the El Niño event occurred, SST in the Timor Sea became lower while at the time of La Niña event it became higher.

Since SST is an easily measured indicator, this study will examine the condition of these parameters in the north and south of Indonesia, which is the ITF crossing line during the occurrence period of El Niño and La Niña. Referring to the research of the study that examined the sea surface height differences between the western Pacific Ocean and the eastern Indian Ocean [8], this study aims to examine the differences in SST of both those oceans at the time of ENSO. The category of SST which to be studied in this research are the variability and the difference of SST in north and south of Indonesia.

\section{Data and Method}

\subsection{Study Area}

The study areas were western Pacific Ocean $\left(125^{\circ}-145^{\circ} \mathrm{E} ; 10^{\circ}-0^{\circ} \mathrm{N}\right)$ and eastern Indian Ocean $\left(110^{\circ}-130^{\circ} \mathrm{E} ; 10^{\circ}-20^{\circ} \mathrm{S}\right)$. It can be seen on Figure 1 . The selection of those region as the study area based on the ITF theory that it moves because of the sea surface height (SSH) differences between the Pacific Ocean and the Indian Ocean [1]. 


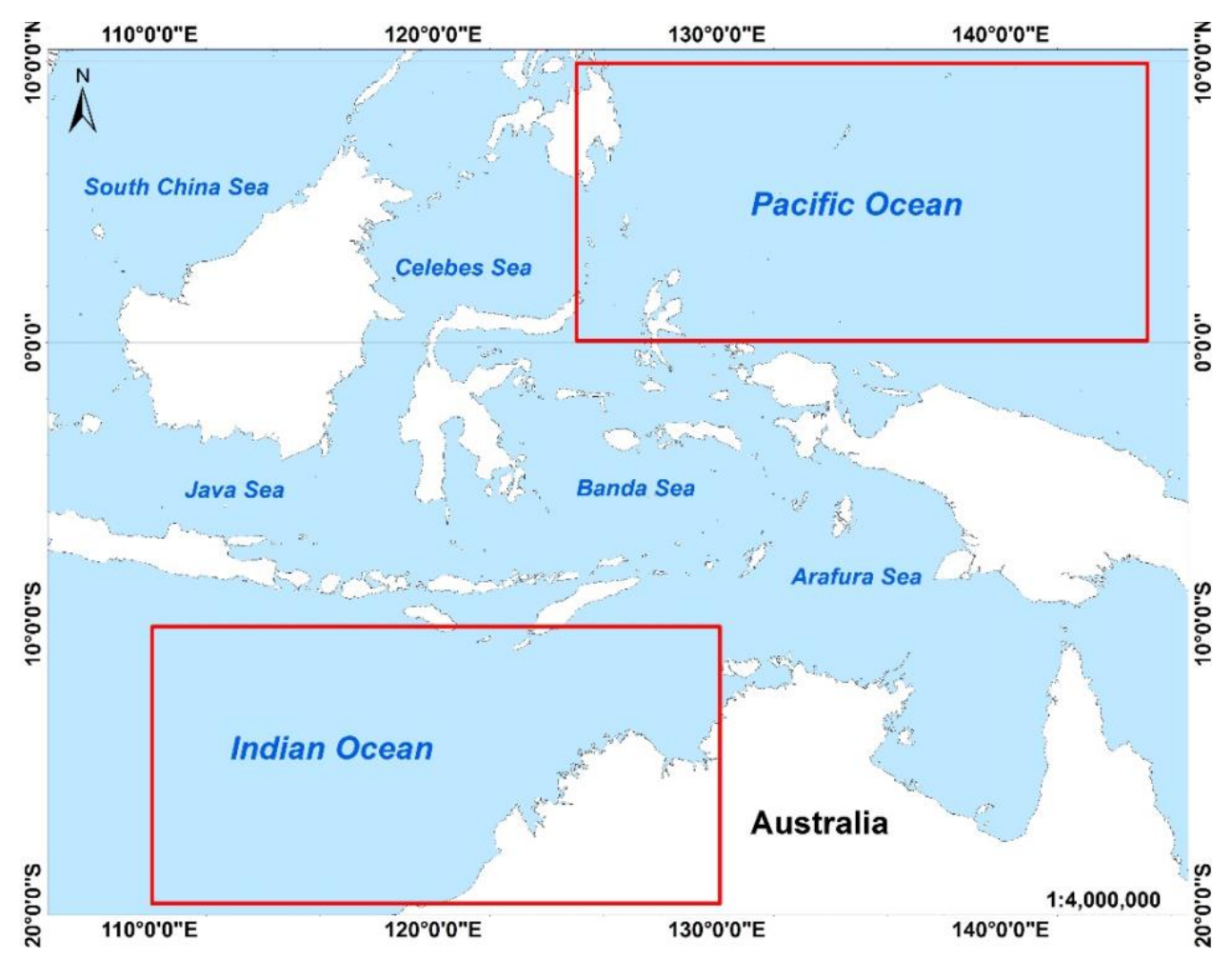

Figure 1: The red boxes are the research location of sea surface temperature.

\subsection{Data}

The daily sea surface temperature (SST) data from January 1982 to December 2015 with $0.25^{\circ} \mathrm{x}$ $0.25^{\circ}$ resolution were obtained from IRI/Ideo Climate Data Library to analyze the variability of SST at the study area. Those daily data were converted to monthly data by using monthly average calculation. SST anomaly data of Nino 3.4 region obtained from NOAA to represent the occurrence of the ENSO.

\subsection{Calculation of Sea Surface Temperature}

Referring to the normal condition of the SST in eastern Pacific Ocean which is commonly higher than the SST in western Indian Ocean [9], the value of SST in the western Pacific Ocean were subtracted by SST in the eastern Indian Ocean for knowing the differences between those both ocean when the ENSO occurred. A simple formulation to calculate the SST difference is as follows:

$$
\triangle S S T=\text { SSTpo }- \text { SSTio }
$$

Where $\triangle S S T$ is the differences of sea surface temperature, SSTpo is the sea surface temperature of the western Pacific Ocean, and SSTio is the sea surface temperature of the eastern Indian Ocean.

\subsection{Determination of the ENSO Phenomenon}

Usually SST anomalies average in a determined region become the indicator to monitor the tropical Pacific activity and the anomalies are computed relative to a base period of 30 years [10]. The Niño 3.4 index and the Oceanic Niño Index (ONI) are the most commonly used indices to define El Niño and La Niña events where the region of Niño 3.4 is located in 5N-5S, 170W-120. 
Niño 3.4 index is the SST anomalies of Nino 3.4 region which may be thought of as representing the average equatorial SST across the Pacific from about the dateline to the South American coast. A 5-month running mean of Niño 3.4 SST anomalies are used to determine the Niño 3.4 index, and El Niño or La Niña events are defined as when the Niño 3.4 SSTs exceeds $+/-0.4^{\circ} \mathrm{C}$ for a period of six months or more. Whereas, ONI uses the same region as the Niño 3.4 index. It uses a 3-month running mean, and to be classified as a full-fledged El Niño or La Niña, the anomalies must exceed $+0.5^{\circ} \mathrm{C}$ or $-0.5^{\circ} \mathrm{C}$ for at least five months [10]. In this study, we used the monthly SST anomaly of Niño 3.4 from NOAA to determine the El Niño and La Niña episode, where the anomaly was taken toward the monthly average of SST Niño 3.4 during the period $1982-2015$. When the monthly anomaly of SST Niño 3.4 is greater than 0.5 then is expressed as El Niño period and when monthly anomaly of SST Niño 3.4 value is lower than -0.5 then expressed as La Niña period, respectively.

\subsection{Calculation of Correlation}

This study conducted a correlation analysis to find out how the relationship is between the parameters of SST in the western Pacific Ocean and eastern Indian Ocean to the SST anomaly in Niño 3.4 region. In addition, correlation analysis was also performed on the SST difference between the western Pacific Ocean and the eastern Indian Ocean to the occurrence of ENSO. The variables which used in the correlation analysis are the anomaly of SST Niño 3.4 as the independent variable (x) which is considered to represent the incidence of El Niño and La Niña and the monthly average data of SST, SST difference in the western Pacific Ocean and the eastern Indian Ocean at the same event as the dependent variable (y). The used correlation equation is Pearson correlation [11] which is formulated as follows:

$$
r_{x y}=\left(n \sum X Y-\sum X \sum Y\right) / \sqrt{ }\left(\left[n \sum X^{2}-(X)^{2}\right]\left[n \sum Y^{2}-(Y)^{2}\right]\right)
$$

Where $r$ is Pearson correlation, $n$ is amount of sample, $x$ is independent variable, and $y$ is dependent variable. The level of relationship between the variables in the correlation analysis is based on the values [12] in Table I.

Table 2: Interpretation of correlation coefficients.

\begin{tabular}{|c|c|}
\hline Interval of correlation & Level of relationship \\
\hline $0-0,199$ & Very low \\
\hline $0,20-0,399$ & Low \\
\hline $0,40-0,599$ & Moderate \\
\hline $0,60-0,799$ & Strong \\
\hline $0,80-1,00$ & Very strong \\
\hline
\end{tabular}

\section{Result and Discussion}

\subsection{Relationship between Niño 3.4 Sea Surface Temperature Anomaly to Sea Surface Temperature in the Western Pacific Ocean and Eastern Indian Ocean}

Based on the calculation of the correlation between Niño 3.4 SST anomaly and SST in the western Pacific Ocean, the correlation value was -0.27 (Figure 2). The small correlation value indicated a weak relationship between those two parameters. The relationship between SST in the western Pacific Ocean and ENSO conditions is the opposite relationship. The declination in SST in the western Pacific Ocean region coincides with an increase in SST in the Niño 3.4 region at the time of 
the El Niño. The opposite result occurred in La Niña condition. Despite the existence of interrelated relationships but the relationship between those two parameters is very small indicated by the correlation value which is only equal to -0.27 .

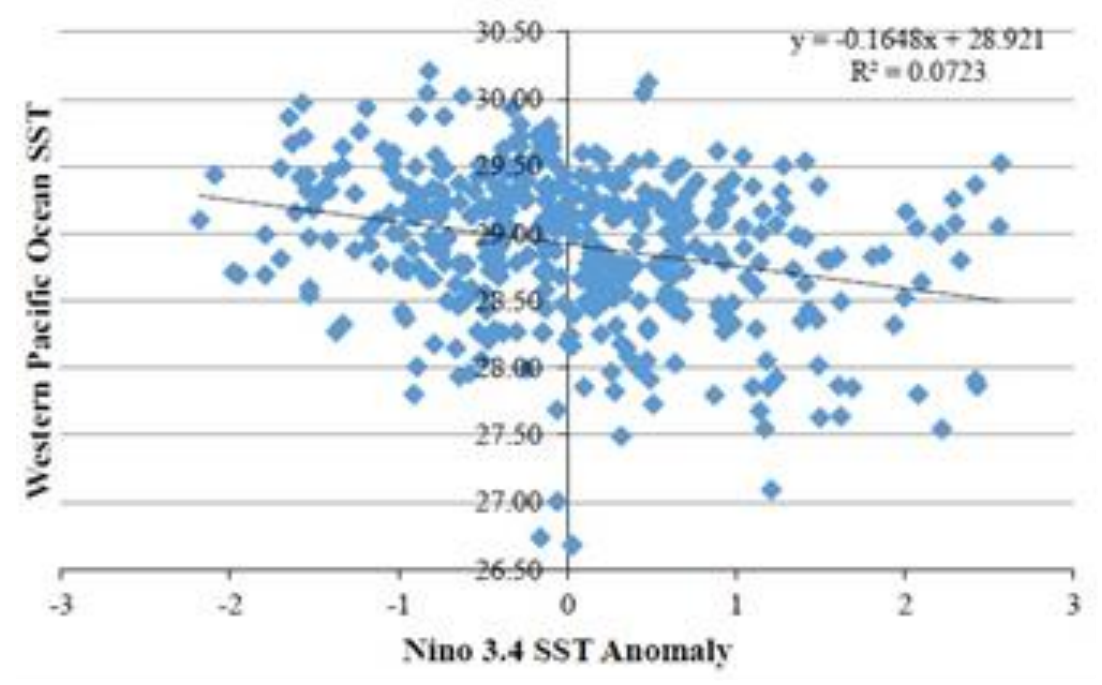

Figure 2: Scatter plot of Niño 3.4 sea surface temperature anomaly and sea surface temperature in western Pacific Ocean.

The calculation of the correlation between Niño 3.4 SST anomaly and SST in the eastern Indian Ocean yielded -0.04 (Figure 3). This value indicates a weak relationship between the two parameters. The negative value indicates that the relationship is reversed, meaning that when the Niño 3.4 SST anomaly is positive or when the El Niño occurs then the SST in the western Pacific Ocean and the eastern Indian Ocean becomes lower. The opposite is true of La Niña. However, the linkage between SSTs in the western Pacific Ocean and ENSO is much stronger than SST in the eastern Indian Ocean.

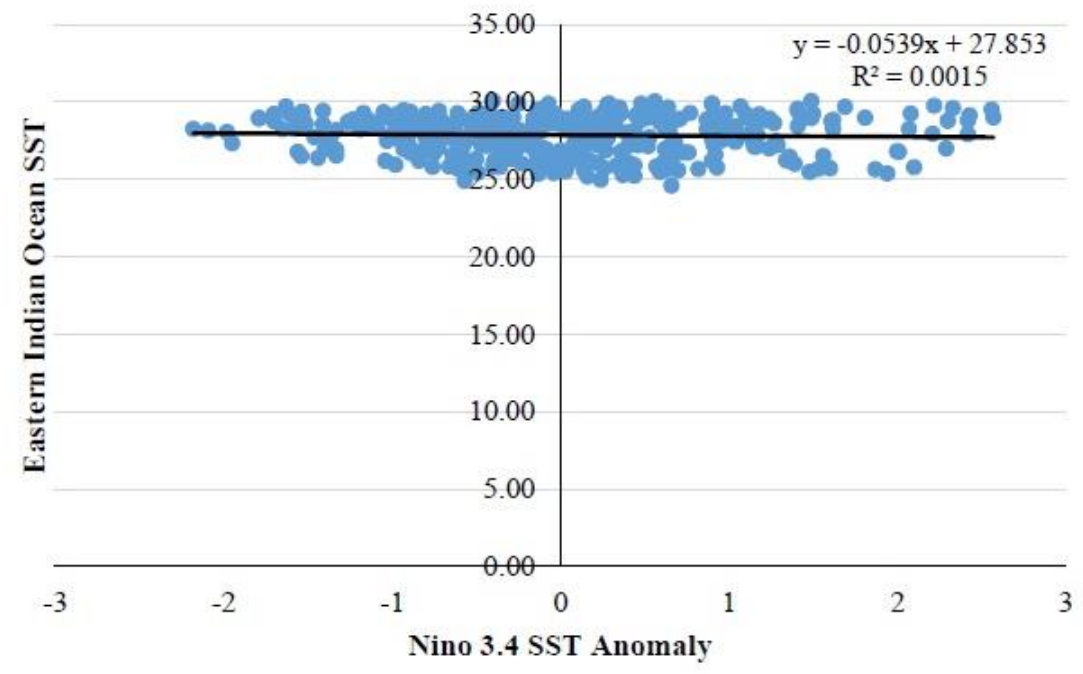

Figure 3: Scatter plot of Niño 3.4 sea surface temperature anomaly and sea surface temperature in eastern Indian Ocean. 
Correlation calculations were also performed on the SST difference in the western Pacific Ocean and the eastern Indian Ocean with SST anomaly of Niño 3.4 region. The calculation results show the correlation value of -0.07 (Figure 4). It shows a weak and opposite relationship.

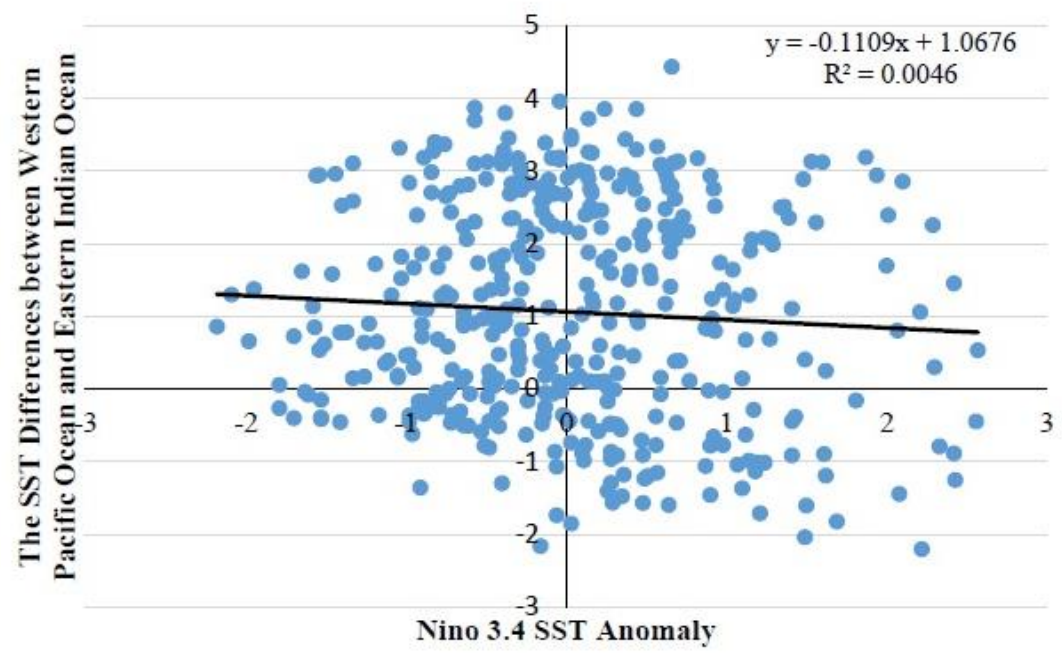

Figure 4: Scatter plot of Niño 3.4 sea surface temperature anomaly and sea surface temperature differences of western Pacific Ocean and eastern Indian Ocean.

\subsection{Sea Surface Temperature Difference between Western Pacific Ocean and Eastern Indian Ocean}

Judging from the result of correlation analysis of small value hence seen there is no close relation between SST difference values at research location with ENSO phenomenon. The difference in SST values varies throughout the year but does not indicate a significant pattern of ENSO events (Table 2).

Table 2. The sea surface temperature difference values between the western Pacific Ocean and the eastern Indian.

\begin{tabular}{|c|c|c|c|c|c|c|c|c|c|c|c|c|}
\hline \multirow{2}{*}{ Year } & \multicolumn{10}{|c|}{ Month } \\
\cline { 2 - 15 } & Jan & Feb & Mar & Apr & May & Jun & Jul & Aug & Sep & Oct & Nov & Dec \\
\hline $\mathbf{1 9 8 2}$ & 0.10 & -0.05 & -0.36 & 0.11 & 1.41 & 2.76 & 2.78 & 2.52 & 2.36 & 1.70 & 0.81 & -0.79 \\
\hline $\mathbf{1 9 8 3}$ & -1.25 & -2.21 & -1.82 & -0.63 & 0.68 & 2.24 & 2.89 & 3.39 & 2.89 & 1.53 & 0.35 & 0.30 \\
\hline $\mathbf{1 9 8 4}$ & -0.24 & -0.59 & -0.44 & -0.06 & 1.06 & 1.87 & 3.10 & 3.18 & 2.69 & -0.24 & 0.65 & -0.15 \\
\hline $\mathbf{1 9 8 5}$ & -0.34 & -1.36 & -0.62 & -0.44 & 0.72 & 1.87 & 2.82 & 3.13 & 2.31 & 2.24 & 1.69 & 0.88 \\
\hline $\mathbf{1 9 8 6}$ & -0.25 & -0.50 & -0.78 & -0.27 & 1.37 & 2.25 & 2.70 & 3.86 & 3.10 & 2.94 & 1.64 & -0.04 \\
\hline $\mathbf{1 9 8 7}$ & -1.01 & -0.28 & -1.01 & -0.02 & 0.97 & 2.09 & 2.50 & 2.89 & 3.14 & 2.52 & 2.00 & 1.23 \\
\hline $\mathbf{1 9 8 8}$ & -0.46 & -1.47 & -1.56 & -0.11 & 0.19 & 1.59 & 2.95 & 2.97 & 2.59 & 1.30 & 0.86 & 0.66 \\
\hline $\mathbf{1 9 8 9}$ & 1.38 & 0.78 & 0.15 & 0.40 & 0.69 & 0.87 & 1.03 & 0.91 & 0.93 & 1.38 & 0.57 & 0.19 \\
\hline $\mathbf{1 9 9 0}$ & -0.44 & -1.18 & -0.58 & -0.17 & 1.18 & 2.22 & 2.52 & 2.45 & 2.40 & 1.44 & 0.18 & -0.49 \\
\hline $\mathbf{1 9 9 1}$ & -1.20 & -0.91 & -0.88 & 0.10 & 0.99 & 1.89 & 2.49 & 2.76 & 2.47 & 1.25 & 1.30 & 0.25 \\
\hline $\mathbf{1 9 9 2}$ & -0.89 & -1.19 & -1.60 & -0.91 & 0.69 & 1.53 & 1.82 & 2.76 & 2.80 & 2.35 & 0.60 & 0.13 \\
\hline $\mathbf{1 9 9 3}$ & -0.86 & 0.46 & -0.70 & -0.66 & 0.80 & 2.07 & 2.79 & 3.25 & 2.97 & 2.00 & 1.60 & 0.37 \\
\hline $\mathbf{1 9 9 4}$ & -1.85 & -2.16 & -1.74 & -0.74 & 0.11 & 0.91 & 1.25 & 1.63 & 1.62 & 0.86 & -0.99 & -1.71 \\
\hline $\mathbf{1 9 9 5}$ & -1.36 & -1.06 & -1.23 & -0.48 & 0.84 & 2.15 & 3.44 & 3.80 & 3.70 & 2.44 & 1.28 & 1.28 \\
\hline $\mathbf{1 9 9 6}$ & 0.12 & -0.31 & -0.80 & 0.04 & 1.53 & 2.34 & 2.61 & 3.18 & 2.83 & 1.82 & 0.49 & 0.14 \\
\hline
\end{tabular}




\begin{tabular}{|c|c|c|c|c|c|c|c|c|c|c|c|c|}
\hline \multirow{2}{*}{ Year } & \multicolumn{10}{|c|}{ Month } \\
\cline { 2 - 14 } & Jan & Feb & Mar & Apr & May & Jun & Jul & Aug & Sep & Oct & Nov & Dec \\
\hline $\mathbf{1 9 9 7}$ & -0.30 & -0.16 & -1.07 & -0.55 & 0.84 & 1.91 & 3.13 & 2.95 & 2.86 & 2.26 & 1.46 & 0.30 \\
\hline $\mathbf{1 9 9 8}$ & -0.88 & -1.44 & -2.04 & -1.46 & 0.39 & 1.84 & 2.70 & 3.27 & 3.41 & 1.72 & 0.90 & 0.62 \\
\hline $\mathbf{1 9 9 9}$ & -0.39 & -0.45 & -0.17 & -0.04 & 1.10 & 1.67 & 2.71 & 2.84 & 2.99 & 1.83 & 0.78 & 0.54 \\
\hline $\mathbf{2 0 0 0}$ & -0.26 & -0.41 & 0.17 & -0.06 & 1.68 & 2.66 & 3.11 & 3.46 & 3.28 & 1.74 & 1.33 & 1.12 \\
\hline $\mathbf{2 0 0 1}$ & -0.32 & 0.17 & 0.24 & 0.60 & 1.16 & 2.73 & 2.91 & 2.70 & 2.75 & 2.11 & 1.38 & 0.75 \\
\hline $\mathbf{2 0 0 2}$ & -0.37 & -0.40 & -0.98 & -0.44 & 0.60 & 2.06 & 3.34 & 3.14 & 3.18 & 2.06 & 1.11 & -0.44 \\
\hline $\mathbf{2 0 0 3}$ & -0.77 & -1.59 & -0.91 & -0.03 & 0.97 & 2.13 & 2.90 & 2.99 & 2.76 & 2.13 & 1.51 & 0.22 \\
\hline $\mathbf{2 0 0 4}$ & 0.02 & 0.10 & 0.27 & 0.38 & 1.03 & 1.88 & 2.90 & 2.80 & 3.12 & 2.38 & 1.18 & 0.39 \\
\hline $\mathbf{2 0 0 5}$ & -0.37 & -1.40 & -1.29 & -0.96 & -0.01 & 2.23 & 2.68 & 3.16 & 2.69 & 2.45 & 0.93 & -0.06 \\
\hline $\mathbf{2 0 0 6}$ & -0.36 & -0.35 & 0.01 & 0.27 & 1.12 & 3.02 & 3.49 & 3.44 & 2.90 & 2.18 & 1.37 & 0.15 \\
\hline $\mathbf{2 0 0 7}$ & 0.16 & -0.77 & -0.47 & 0.40 & 1.04 & 2.59 & 3.17 & 3.88 & 3.32 & 2.53 & 1.14 & -0.08 \\
\hline $\mathbf{2 0 0 8}$ & 0.06 & -0.40 & -0.36 & -0.16 & 0.94 & 1.79 & 3.19 & 3.96 & 3.02 & 1.95 & 1.10 & 0.89 \\
\hline $\mathbf{2 0 0 9}$ & 0.47 & 0.27 & -0.46 & -0.63 & 1.18 & 2.26 & 2.25 & 2.99 & 2.62 & 1.74 & 0.41 & -0.15 \\
\hline $\mathbf{2 0 1 0}$ & -0.38 & -1.13 & -1.04 & -0.77 & 0.68 & 2.07 & 3.19 & 3.11 & 2.94 & 1.62 & 0.85 & -0.03 \\
\hline $\mathbf{2 0 1 1}$ & 0.73 & 0.64 & 0.48 & 0.59 & 1.30 & 2.23 & 2.83 & 2.80 & 3.37 & 2.40 & 1.29 & 0.16 \\
\hline $\mathbf{2 0 1 2}$ & -0.31 & -0.50 & 0.10 & 0.41 & 1.87 & 3.27 & 3.86 & 4.44 & 3.30 & 1.75 & 0.51 & -0.25 \\
\hline $\mathbf{2 0 1 3}$ & -0.51 & -1.30 & -0.36 & -0.06 & 0.82 & 2.36 & 2.91 & 3.04 & 3.19 & 1.68 & 0.59 & 0.48 \\
\hline $\mathbf{2 0 1 4}$ & 0.48 & 0.05 & -0.86 & -0.47 & 0.92 & 2.55 & 2.99 & 3.72 & 2.95 & 1.99 & 0.84 & 0.12 \\
\hline $\mathbf{2 0 1 5}$ & -0.07 & -1.15 & -1.57 & -0.78 & 1.14 & 2.06 & 2.30 & 3.20 & 2.40 & 1.06 & 0.54 & -0.44 \\
\hline Average & $\mathbf{- 0 . 3 5}$ & $\mathbf{- 0 . 6 5}$ & $\mathbf{- 0 . 7 1}$ & $\mathbf{- 0 . 2 2}$ & $\mathbf{0 . 9 4}$ & $\mathbf{2 . 1 2}$ & $\mathbf{2 . 7 7}$ & $\mathbf{3 . 0 8}$ & $\mathbf{2 . 8 2}$ & $\mathbf{1 . 8 6}$ & $\mathbf{0 . 9 5}$ & $\mathbf{0 . 1 9}$ \\
\hline
\end{tabular}

Although the correlation value between the anomalies of Niño 3.4 SST anomaly and SST in both oceans has a small correlation value, but when it analyzed as the composite analysis for the comparison between the difference of both sides of the ocean on average from 1982-2015 to the value of SST difference when the occurrence of the ENSO, it indicated the existence significant differences (Figure 5).

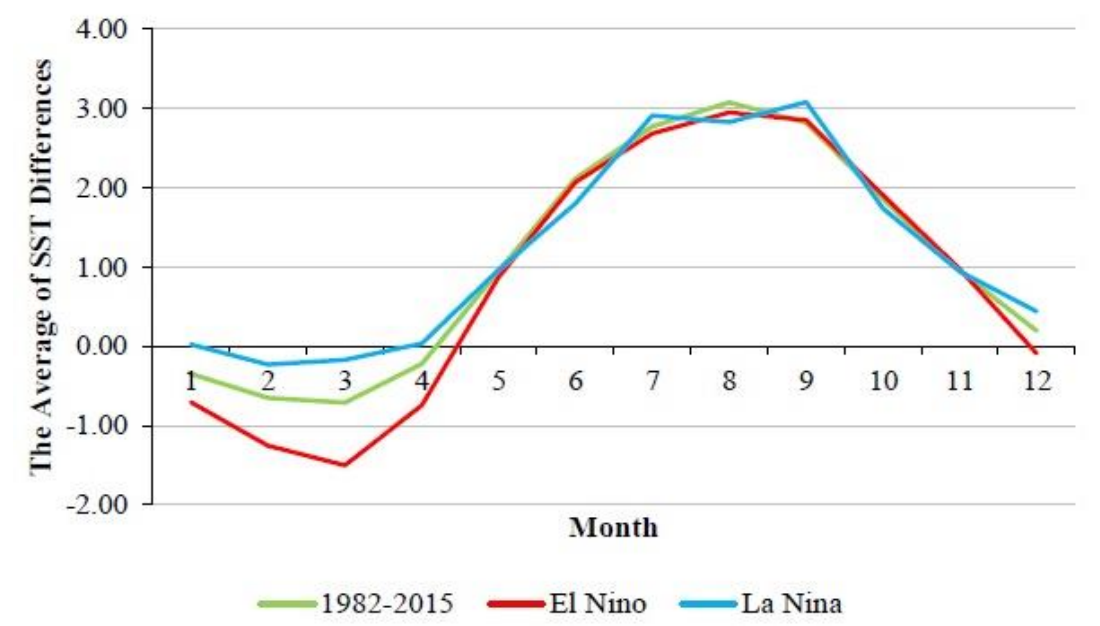

Figure 5: Average comparison graph of sea surface temperature differences of western Pacific Ocean and eastern Indian Ocean. Green line: average along 1982-2015, red line: average when El Niño events, and blue line: when La Niña events.

When El Niño occurs in the period around December to April the SST difference between the western Pacific Ocean and the eastern Indian Ocean has a smaller value than at the time of La Niña. It can be seen that in January, February, and March SST in the eastern Indian Ocean were higher 
than the SST in the western Pacific Ocean and the SST differences between those two oceans became larger when El Nino happened than while the occurrence of La Nina.

When the ENSO phenomenon occurs in the mid-year period from May to November, the temperature difference between the western Pacific Ocean and the eastern Indian Ocean tends to be similar and there is no significant difference. In May, June, July, August, September, October, and November the trends of SST in western Pacific Ocean are higher than the SST in the eastern Indian Ocean and it had the same condition with El Nino and La Nina and tend to be no differences from the normal conditions. In December, where the value of the SST in western Pacific Ocean remains higher than the SST in eastern Indian Ocean but in El Niño event, the SST differences becomes smaller than when La Nina happened.

\subsection{The Influence of ENSO on Sea Surface Temperature Variability in the Western Pacific Ocean and Eastern Indian Ocean}

Based on Niño 3.4 SST anomaly data in $1982-2015$, the data processing results correlated with SST in the Pacific Ocean and Indian Ocean in 1982 - 2015 resulted in small correlation coefficient values. The correlation coefficient value between the SST of the western Pacific Ocean with the SST Niño 3.4 anomaly is -0.27 and the correlation coefficient value of SST of the East Indian Ocean with SST Niño3.4 anomaly is -0.04. It showed that the relationship between ENSO phenomena to SST in both oceans is weak.

The relationship between SSTs in both locations and the Niño 3.4 SST anomaly is an opposite relationship. The criteria of the opposite relationship are shown by the result of negative correlation coefficient. In addition, it can also be seen from the tendency of the slope of the correlation graph shown in Figure 2 and Figure 3.

The opposite relationship of the correlation calculations shows that when there is an increase of SST anomaly in Niño 3.4 there will be a decrease of SST in the western Pacific Ocean and the eastern Indian Ocean. This indicates that when an El Niño occurs where the anomalous SST Niño 3.4 increases, the SST in both oceans will be lower than the normal condition. When an SST anomaly in the Niño 3.4 region is lower than the normal condition it will have an impact on increasing SST in the western Pacific Ocean and eastern Indian Ocean and this condition indicated as the La Niña event.

The El Niño phenomenon is indicated by positive SST anomalies in the Pacific Ocean. El Niño deals with the weak and warm ocean currents along the coast of South America, which replaces the cold currents of the Peruvian currents. These symptoms generally appear every 2 to 7 years [4]. In El Niño event, there will be an increase in the temperature of the sea surface in the eastern Pacific region and make the air pressure difference between Darwin and Tahiti high [13].

The opposite relationship between the SST in the western Pacific Ocean and the eastern Indian Ocean towards ENSO or the SST Niño 3.4 anomaly obtained from the results of this study is related to the phenomenon of shifting hot pools in the Pacific Ocean. As explained earlier that at the time of El Niño there was a shift of hot pools from the western Pacific to the eastern Pacific [14]. There is a shift in the hot water pool that causes the sea surface temperature in the Pacific Ocean to vary. Hot water pools during normal conditions are located in the western Pacific Ocean but when the El Niño occurs the position of the hot pool undergoes a shift. Hot pools are moving eastward causing SST conditions in the western Pacific Ocean to decrease. The opposite is true of La Niña. When La Niña occurs, a hot pool in the western Pacific Ocean experiences an increase in temperature. That is why the SST conditions in the western Pacific Ocean have an opposite relationship to the SST anomaly in Niño 3.4 region where the location of Niño 3.4 is to the east of the Pacific Ocean. 
The comparative analysis which conducted on the value of SST in both oceans to know the difference of SST at ENSO then obtained the result that there is variation to the SST difference in both oceans. The calculation results of SST difference of the western Pacific Ocean with the eastern Indian Ocean at the time of El Niño showed negative results while at the time La Niña yields a positive value (Table II). This indicates that in the case of El Niño, the SST in the western Pacific Ocean is lower than the SST in the eastern Indian Ocean whereas the SST in the western Pacific Ocean is higher than the SST in the eastern Indian Ocean at the time of La Niña. The opposite relationship between the SST Niño 3.4 anomaly with the SST of the western Pacific Ocean and the eastern Indian Ocean can also be seen from the slope of the correlation graph in Figure 4.

Judging from the calculation of the average value of SST difference during the incidence of El Niño and La Niña during the period 1982 - 2015 in both oceans is seen that when the El Niño occurs the difference in the average value of SST at the time of the incident El Niño show the value of negative difference while At the time La Niña showed a positive value (Figure 5). However, based on the graph in Figure 5 showed the difference in SST difference values when the El Niño and La Niña are only seen if the ENSO phenomenon occurs at the beginning of the year (January April) and the end of the year (December). When the ENSO phenomenon occurs in November to May, the SST difference values in both oceans will be higher at La Niña than at the time of the El Niño. In the case of El Niño, the average difference between SST will be below the average SST difference during the years 1982 - 2015. At La Niña the average value of the SST difference is above the mean value of the SST difference during the years 1982 - 2015 If the ENSO phenomenon occurs in the mid-year period from June to November, the SST difference between the western Pacific Ocean and the eastern Indian Ocean tends to be the same and resembles the average value pattern of the SST difference between 1982 and 2015.

\section{Conclusion}

Based on the results and discussion of this study, it can be concluded that ENSO (El Niño Southern Oscillation) has had different effects on SST variations in the western Pacific Ocean and eastern Indian Ocean especially at the beginning of the year and at the end of the year.

\section{Acknowledgment}

The authors would like to thank IRI/ Ideo Climate Data Library for providing the sea surface temperature data and also NOAA for providing the Niño 3.4 sea surface temperature anomaly data.

\section{References}

[1] B. Mayer, P.E. Damm, T. Pohlmann, and S. Rizal, "What is driving the ITF? An iillumination of the Indonesian Throughflow with a numerical nested model system," Dynamics of Atmospheres and Oceans, vol. 50. Elsevier, 2010.

[2] M. Safitri, S.Y. Cahyarini, and M.R. Putri, M.R., "Variations of Indonesia Throughflow and oceanographic parameters in the Timor Sea as an indicator of ENSO events," Journal of Tropical Marine Science and Technology. Bogor, Indonesia: Agriculture Institute of Bogor (IPB), 2012.

[3] W.S. Pranowo, A.R.T.D. Kuswardhani, T.L. Kepel, U.R. Kadarwati, S. Makarim, and S. Husrin, Revealing the Indonesia Throughflow. Jakarta, Indonesia: Marine and Fisheries Resources Research Center-Marine and Fisheries Research Agency Department of Marine and Fisheries, 2005.

[4] J.P. Peixoto and A.H. Oort, Physic of Climate. New York: American Institut of Physics, 1995.

[5] A. Arora, S.A. Rao, R. Chattopadhyay, T. Goswami, G. George, C.T. Sabeerali, "Role of Indian Ocean SST variability on the recent global warming hiatus, "Global and Planetary Change, vol. 143, Elsevier, 2016, pp. 21 30. 
[6] R.W. Reynolds and T.M. Smith, “A high-resolution global sea surface climatology,” J. Climate, vol. 8, no. 6, 1995, pp. 1571-1583.

[7] W. Estiningtyas, "Time lag influence between rainfall and nino 3.4 sea surface temperature to the performance of rainfall prediction model," Journal of Meteorology and Geophysics, vol. 8, no. 1, Jakarta, Indonesia: Indonesian Agency for Meteorology Climatology and Geophysics (BMKG), 2007, pp. 13 - 26.

[8] H.A. Rejeki, Kunarso, and Munasik, "The effect of ENSO to the variability of sea surface height in western Pacific Ocean and eastern Indian Ocean and its connectivity to the Indonesia Throughflow, " IOP Conf. Series: Earth and Environmental Science, vol. 55, 2017.

[9] F. Liu, L. Zhou, J. Ling, X. Fu, G. Huang, "Relationship between SST anomalies and the intensity of intraseasonal variability," Theor Appl Climatol, vol. 124, Verlag Wien, Austria: Springer, 2016, pp. 847-854.

[10] D. Trenberth, "The definiton of El Niño," Bulletin of The American Meteorological Society, vol. 78, no. 12, 1997, pp. 2771-2777.

[11] Sudjana, Statistical Method, 6th ed. Bandung, Indonesia: Tarsito, 1996.

[12] Sugiyono, Quantitative Qualitative and R \& D Research Methods. Bandung, Indonesia: Alfabeta, 2009.

[13] B. Irawan, "The climate anomaly phenomenon El Niño and La Niña - long term trend and its influence on food production," Agro Economic Research Forum, vol. 24, no. 1, 2006, pp. 28-45.

[14] Irkhos, "The effect of sea surface temperature of Niño 3 region in Pacific Ocean to the rainfall of Sumatra Region," J. Gradient, vol. 3, no. 1, Bengkulu, Indonesia: University of Bengkulu, 2007, pp. 196-199. 